\title{
LOS CONTRATOS MATRIMONIALES; REFLEJO DE LA SOCIEDAD ALICANTINA DEL ANTIGUO RÉGIMEN
}

\author{
Por Juan Antonio CASTAÑO DÍAZ
}

El presente artículo es un resumen de la tercera parte de la memoria de licenciatura presentada en la Universidad de Alicante, en 1983, con el título de: Los contratos matrimoniales en el antiguo régimen, y que fue dirigida por D. Enrique Giménez López.

La finalidad de nuestro trabajo ha sido acercarnos a la sociedad alicantina del siglo XVIII, desde una perspectiva no muy usual en España, que puede aportarnos una serie de matices que ayuden a la comprensión de la sociedad del antiguo régimen.

La fuente que nos permite este estudio es el contrato matrimonial; que por sus características, pues se trata del documento que aclara la situación de los bienes del nuevo matrimonio, nos enseña las bases de la economía familiar y la situación jurídica de los cónyuges respecto a los distintos bienes que constituyen el capital del nuevo matrimonio (bienes dotales, arras, bienes parafernales, bienes propios del marido, y bienes gananciales).

En nuestra memoria de licenciatura, hacemos primeramente un análisis de la situación jurídica de los cónyuges, respecto a esos bienes del patrimonio familiar y a continuación estudiamos con detenimiento la estructura y tipología de las actas utilizadas en nuestro trabajo. Sin embargo, debido a la limitada extensión del presente artículo, hemos optado por hacer hincapié en la tercera parte de la memoria de licenciatura, que se ocupa directamente del aspecto social, en detrimento de las dos primeras partes ya indicadas.

Digamos primeramente, que para la elaboración del presente trabajo nos hemos servido de los protocolos notariales conservados en el Archivo Histórico Provincial de Alicante (A.H.P.A.), entre los años 1750 y 1775. Concretamente hemos consultado 278 libros de protocolos pertenecientes a 38 notarios, lo que supone la totalidad de los protocolos que de los años estudiados se conservan en el citado archivo. 
Fundamentalmente nuestro estudio se ha centrado en las actas de contratos matrimoniales, que engloban principalmente: un primer tipo constituido por las cartas dotales, con sus dos vertientes: de una parte las recepciones de dote y de otra las recepciones de arras; el segundo tipo lo constituyen las cartas de boda y el tercero y último las donaciones; pero además de estos contratos matrimoniales, hemos estudiado también los ingresos de religiosas y los ingresos sacerdotales.

La fuente utilizada para nuestro trabajo, como nos dice Jacques Lafon, es «le produit direct, immediat, de la société».(1) Esta se puede alegar como la primera de sus ventajas, pues se trata de una fuente que refleja de un modo directo el estado de la sociedad.

Pero para poder indicar las ventajas de los contratos matrimoniales, hay que exponer primeramente los datos que nos aportan las citadas actas, que en el mejor de los casos son los siguientes:

- Nombre y apellidos de la novia y el novio, así como también de sus padres y la profesión y vecindad de todos ellos.

- Identidad de la persona que aporta el dinero o los bienes.

- Condiciones con las que se entrega el dinero o los bienes.

-Cantidad de dinero aportada y relación de los objetos que constituyen esa cantidad de dinero.

-Y por último, el nombre de los testigos y naturalmente, lugar y fecha donde se cumplimentó el acta.

Estos datos nos permiten hacer un estudio de la estructura socioprofesional, pues el número de actas que aportan los datos necesarios, tales como la profesión del novio, la cantidad de dinero entregado y la profesión del padre de la novia, es lo suficientemente elevado para poder abordar con garantías de fiabilidad un estudio de este tipo. Así pues, de los 346 contratos matrimoniales estudiados, 214 contienen la profesión del novio y una valoración de la dote o de la donación propternuptias (arras), lo que significa casi el $62 \%$ de los contratos matrimoniales.

Por otra parte, la tarea de estudiar las alianzas matrimoniales entre los distintos grupos socioprofesionales se muestra más difícil y menos fiable, pues son solamente 81 casos los que nos aportan la profesión del novio y del padre de la novia, así como también la valoración de la dote o de las arras, lo que supone el $23,5 \%$ del total de los contratos matrimoniales, de tal modo que los resultados de nuestro trabajo sobre este tema, han de ser observados con las debidas reservas, si bien pensamos que están bastante próximos a la realidad por la coherencia de los resultados obtenidos.

Otro aspecto que hemos podido afrontar, es la propia naturaleza de las donaciones, mediante el análisis de las relaciones de objetos que contienen casi el $68 \%$ de las actas analizadas ( 231 actas), atendiendo sobre todo al donante que aparece en 307 contratos matrimoniales, lo que supone el $88,7 \%$ del total.

La localidad del novio, es un dato bastante frecuente en los contratos matrimoniales, el 93,3\% de las actas nos informan sobre la vecindad de alguno de los cónyuges y el 70,4\% de la de ambos cónyuges, lo que nos permite hacer un análisis fiable de lás relaciones entre Alicante y su gobernación sobre todo, pero también con el resto de España y con Europa en cuanto a las relaciones matrimoniales. 
Además, los datos que hemos indicado nos van a facilitar también un estudio de la distribución espacial en Alicante y su gobernación de los distintos grupos socioprofesionales, así como también, mediante el análisis de las cantidades recibidas en concepto de dote y arras, podemos apuntar algunos datos que nos aproximan a la comprensión de la distribución de la riqueza entre Alicante y su gobernación.

El dato que con más frecuencia aparece es la valoración de las donaciones, siendo además el que nos ayuda a establecer una jerarquía dentro de los distintos grupos socioprofesionales. Sin embargo, es también el dato que con más precaución hay que utilizar, por los múltiples factores que pueden influir en él.

Tirat ${ }^{(2)}$ y Poussou ${ }^{(3)}$, basaron su crítica a este tipo de fuente, sobre todo en la representatividad real de las cantidades que se entregan en concepto de dote, que por depender de varios factores, como son el número de hermanos y hermanas y el que se trate de viudos o de primeras nupcias, hay que manejar con las debidas precauciones y por ello, nosotros hemos hecho constar a lo largo de nuestro trabajo, los casos de viudas y viudos, pero en cuanto al número de hermanos, es una dificultad que hemos tenido que asumir por la imposibilidad de obtener estos datos para todos los contratos matrimoniales que han sido objeto de nuestro análisis.

Por otra parte, también hay que pensar que entre los campesinos, este tipo de contratos se efectuaría con menos asiduidad que entre los grupos socioprofesionales más vinculados a la ciudad y con más medios económicos. Además, a la hora de reseñar en el acta la profesión del otorgante, es más comprensible que se omita la profesión de un labrador que la de un cirujano o un abogado.

Por todo lo dicho anteriormente, hay que dejar bien claro que es posible que el grupo socioprofesional de los campesinos, se encuentre ligeramente subestimado en nuestros datos, si bien hay que decir que todos los grupos socioprofesionales están representados en los contratos matrimoniales, lo que indica que este tipo de acta, no se realizaba exclusivamente por un grupo determinado, encontrando ejemplos de todo el espectro social.

Antes de adentrarnos en los resultados de nuestro estudio de la estructura social de Alicante en el siglo XVIII, es necesario aclarar que en una sociedad preindustrial como la que analizamos, las dotes constituyen un factor considerable de la renta acumulada o patrimonio de las personas, de tal modo que no es extraño que se piense en éstas como en uno de los medios más usuales de acumulación de capital para emprender cualquier tipo de empresa, ${ }^{(4)}$ siendo también, en los últimos años del siglo XVII y primeros del siglo XVIII, utilizadas por la alta nobleza española como pretexto para hipotecar sus propiedades y obtener las cantidades de dinero efectivo necesarias para mantener su tren de vida. ${ }^{(5)}$

Las cantidades que se pagaban en concepto de dote en el siglo XVIII en algunos casos llegaron a ser tan elevadas que provocaron la crítica de arbitristas e ilustrados, que las consideraban como un obstáculo para el aumento de la población. ${ }^{(6)}$ Reyes como Carlos I, Felipe II, y Felipe IV, ya advirtieron este problema e intentaron solucionarlo mediante constantes limitaciones a las cantidades de dinero que se podian entregar en estas dotes. ${ }^{(7)}$ Por otra parte en nuestra investigación hemos encontrado dotes desde 10 libras, ${ }^{(8)}$ hasta 42.026 libras, 4 sueldos y 4 
dineros, ${ }^{(9)}$ lo que supone una media de 585 libras, 17 sueldos y 7 dineros, sin embargo, este dato hay que manejarlo con precaución, pues el coeficiente de variación es altísimo $(462,99)$, por lo que decidimos calcular la mediana, que por sus características no tiene en cuenta los valores extremos, obteniendo como resultado 133 libras y 1 sueldo, dato éste que se acerca más a la realidad, pues el 90,8\% de las dotes no alcanzan las 1.000 libras y el $80,1 \%$ no llegan a las 400 libras.

De este modo, hemos dividido las dotes analizadas por nosotros, en dos grupos:

1.-Las inferiores a las 1.000 libras, que serán las más numerosas y cuya finalidad sería el ayudar a soportar las cargas del matrimonio, siendo una especie de fondo económico extraordinario que aporta a la nueva familia una mediana seguridad para poder salir adelante en sus primeros años. Dentro de este primer grupo encontramos desde los trabajadores del campo y los labradores hasta los pequeños funcionarios, médicos, escribanos, etc... y los pequeños comerciantes.

No debemos subestimar estas pequeñas dotes, puesto que cumplían una función importante, como es la de animar a los jóvenes a contraer matrimonio al darles una cierta seguridad económica.

2.- Sin embargo, ya hemos indicado que hay otro tipo de dotes; que son las que sobrepasan las 1.000 libras y que constituyen el $9,1 \%$ de las mismas. Los protagonistas de estas dotes son los grandes comerciantes (mayoristas) y la nobleza local.

En este caso el objetivo de la dote y su significación, transciende la mera ayuda a soportar las cargas del matrimonio, por el gran número de intereses económicos y sociales que juegan para fijar las cantidades a entregar. En este caso nos encontramos ante lo que podríamos denominar como una verdadera estrategia matrimonial. ${ }^{(1))}$

Las casas más importantes de la nobleza local intentarán acrecentar su poder y su prestigio mediante enlaces matrimoniales entre ellos o con casas más importantes y la pequeña nobleza intentará emparentar con la alta nobleza local, siendo fundamental en este tipo de enlaces las cantidades aportadas en dote por la esposa; o en su caso las arras que el novio pueda proporcionar.

Por su parte, la dote también juega un papel importante dentro del grupo de los grandes comerciantes, pues el sueño dorado del comerciante español del siglo XVIII es el llegar a vivir noblemente y a ser posible emparentar con alguna casa noble, para lo cual, ha de romper la aversión que la nobleza tiene a contraer matrimonio con plebeyos, hasta tal punto que algunos teólogos calificaban este hecho de pecado mortal. (11) Pero además, los comerciantes, hombres de mente abierta para los negocios, buscaban siempre cualquier matrimonio que les reportara beneficios, que si no podían ser de prestigio social, sin duda lo serán en el terreno meramente económico.

En el caso de las arras, que es la donación que el marido hace a su esposa a la hora del matrimonio, para que estos bienes gocen de los mismos privilegios que los bienes dotales, digamos que se repite de un modo similar a las dotes la doble división entre arras superiores e inferiores a las 1.000 libras, si bien hay que resaltar que la mediana en el caso de las arras es algo superior a la de las dotes, concretamente es de 200 libras. 
La finalidad de las arras es doble: por una parte pretende asegurar una existencia decorosa a la mujer en caso de viudez (hemos de pensar que en el siglo que estudiamos, la muerte visitaba con relativa frecuencia a las familias españolas); mientras que por otra parte, también era una ayuda para obtener ese fondo económico que como ya explicamos, daba a la familia una cierta seguridad, por tratarse de unos bienes protegidos (no olvidemos que las arras se constituyen como aumento de la dote, gozando de los mismos privilegios que ésta).

Tras este análisis previo, estamos ya en condiciones de comenzar nuestro estudio de la sociedad alicantina del setecientos, por lo cual primeramente distribuiremos los contratos matrimoniales según los distintos sectores de actividad, lo que nos proporcionará una primera aproximación a la estructura profesional de Alicante y su gobernación, para a continuación emprender un estudio socioprofesional que nos facilitará un conocimiento más profundo de la misma.

Por lo que respecta a la distribución de la población en los tres sectores de actividad, Gonzalo Anes con respecto a la totalidad de España en 1787, nos señala un predominio absoluto del sector primario que recoge el $71 \%$ de la población activa, mientras que los sectores secundario y terciario le seguían muy de lejos, concretamente concede un $12 \%$ para el secundario y el $17 \%$ restante para el sector terciario. ${ }^{(12)}$

Sin embargo, en el caso concreto de Alicante y su gobernación, estas diferencias se ven suavizadas, como se puede apreciar en el cuadro 1 .

\section{CUADRO 1}

Distribución de la población activa por sectores productivos en 1754 y 1786

\begin{tabular}{|c|c|c|c|c|}
\hline SECTORES & $1754^{\circ}$ & $\%$ & 1786 & $\%$ \\
\hline 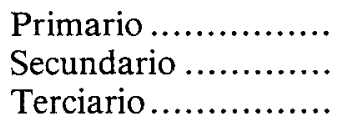 & $\begin{array}{r}1.747 \\
754 \\
908 \\
\end{array}$ & $\begin{array}{l}48,2 \\
23,5 \\
28,3 \\
\end{array}$ & $\begin{array}{l}3.275 \\
1.403 \\
1.744 \\
\end{array}$ & $\begin{array}{l}51,0 \\
21,8 \\
27,2 \\
\end{array}$ \\
\hline TOTAL ............ & 3.209 & 100,0 & 6.422 & 100,0 \\
\hline
\end{tabular}

FUENTE: Enrique Giménez: Alicante en el siglo XVIII. Economía de una ciudad portuaria en el antiguo régimen, p. 187 (reproducción parcial).

Mientras que nuestros datos recogidos en el cuadro 2, nos muestran un sector primario en cabeza (acapara el $38,3 \%$ de las dotes), seguido sin mucha diferencia por los sectores secundario y terciario. En líneas generales, se podría decir que se asemeja a la distribución por sectores que nos proporciona el padrón de 1731 cuyos datos fueron recogidos por Enrique Giménez, ${ }^{(13)}$ obteniendo un $37,2 \%$ de la población para el sector primario y un $34,7 \%$ y $28,2 \%$ para los sectores secundario y terciario respectivamente.

Sin embargo, la media de las dotes es mayor en el sector terciario que en ninguno de los otros dos y menor en el primario que acapara el mayor número de población activa, lo que nos indica que en líneas generales, las profesiones vinculadas al sector terciario gozan de una mayor estima social además de unos mayo- 
res beneficios económicos, mientras que el sector primario compuesto por labradores y jornaleros recibe las dotes más bajas, puesto que su poder económico y su estima social son también los más bajos.

\section{CUADRO 2}

Distribución del número de dotes por sectores productivos, 1750-1775(14)

\begin{tabular}{|c|c|c|c|c|c|c|}
\hline SECTORES & $\begin{array}{l}\text { Núm. } \\
\text { dotes }\end{array}$ & $\%$ & $\begin{array}{c}\text { Dinero } \\
\text { total }\end{array}$ & $\%$ & $\begin{array}{c}\text { Media } \\
\text { de dotes }\end{array}$ & $\%$ \\
\hline Primario & 82 & 38,3 & 2.256 .110 & 9,9 & 27.513 & 12,4 \\
\hline & 70 & & 3.74 & 16 & $47.233,73$ & 21,3 \\
\hline Terciario ............... & 62 & 28,9 & 16.718 .580 & 73,5 & $146.675,50$ & 66,2 \\
\hline TOTAL & 214 & 100,0 & 22.724 .463 & 100,0 & $221.422,76$ & 100,0 \\
\hline
\end{tabular}

FUENTE: A.H.P.A. Protocolos. Elaboración propia

Por lo que respecta al sector secundario, hay que decir que está más cerca del primario que del terciario en cuanto a la medida de sus dotes, lo que indica que sus profesiones gozan de un prestigio social superior al de los campesinos, pero su situación económica está muy lejos de alcanzar a la del terciario.

Por su parte, las arras nos informan muy frecuentemente de la profesión del donante, lo que nos permite elaborar el cuadro 3, en el que se aprecia cómo el sector secundario ya no se encuentra en el segundo lugar en cuanto a las aportaciones; como ocurría con las dotes, sino que ahora queda en último lugar, mientras que el mayor número de arras se encuentra en el sector terciario, que, además, es el que cuenta con la media más alta. Este fenómeno se produce por ser las profesiones del sector terciario las de mayor prestigio social y poder económico, por lo que en no pocas ocasiones, para conseguir un matrimonio ventajoso que les permita subir un peldaño más en la escala social, se ven obligados a proveer de arras a sus hijos varones, mientras que en los sectores primario y secundario la posibilidad de ascenso social es más restringida. Esto explica también que las arras del sector terciario consigan superar las 1.000 libras, mientras que en los sectores primario y secundario ninguna de sus arras logran alcanzar esa cifra.

\section{CUADRO 3}

Distribución del número de arras por sectores productivos, 1750-1775

\begin{tabular}{|c|c|c|c|c|c|c|}
\hline SECTORES & $\begin{array}{l}\text { Núm. } \\
\text { arras }\end{array}$ & $\%$ & $\begin{array}{c}\text { Dinero } \\
\text { total }\end{array}$ & $\%$ & $\begin{array}{c}\text { Media } \\
\text { arras }\end{array}$ & $\%$ \\
\hline Primario . & 12 & 30 & 712.003 & 8,4 & $59.333,58$ & 14,9 \\
\hline & 4 & 10 & & & & 4,2 \\
\hline Terciario ...................... & 24 & 60 & 7.562 .231 & 90,0 & $315.092,95$ & 80,5 \\
\hline TOTAL .............. & 40 & 100 & 8.399 .394 & 100,0 & $391.164,99$ & 100,0 \\
\hline
\end{tabular}

FUENTE: A.H.P.A. Protocolos. Elaboración propia 
Ahora bien, estos sectores no son homogéneos en su composición interna, de tal modo que se hace conveniente un estudio más detenido de los mismos.

-El sector primario es el más homogéneo y contiene dos profesiones: los labradores y los trabajadores del campo. La diferencia entre ambos estriba en que los primeros disponen de unas tierras generalmente arrendadas, que les permiten vivir ayudándose en ocasiones con determinados trabajos artesanos y en tiempos de malas cosechas trabajando tierras ajenas por un jornal, mientras que los trabajadores son jornaleros sin tierras propias o con una pequeña parcela que no les da lo suficiente para subsistir.

- Sin embargo, atendiendo a las dotes que reciben unos y otros, no hay diferencias excesivas, pues la dote media de los labradores es de 118 libras, 18 sueldos y 7 dineros y la de los jornaleros de 100 libras, 8 sueldos y 2 dineros.

-El sector secundario por su parte, incluye a todos los artesanos y en él se aprecian primeramente dos grupos claramente definidos: de una parte los maestros, de los que hemos contabilizado 35 y que reciben como dote media 293 libras, 17 sueldos y 7 dineros, y de otra los oficiales, que sólo son 15 con una dote media sensiblemente inferior, 118 libras, 10 sueldos y 4 dineros. Además hemos de indicar 20 casos que no están calificados de maestros ni de oficiales, con una dote media de 178 libras y 5 dineros, lo que nos hace pensar que englobarán ejemplos de ambas categorías.

El encontrar mayor número de maestros que de oficiales nos hace pensar en una cantidad importante de talleres en los que trabajaría ei maestro sólo o con algún aprendiz, y en menos ocasiones con algún oficial, cuya participación en los beneficios del taller no debió ser muy elevada, a juzgar por las escasas dotes que reciben en sus matrimonios. Según Domínguez Ortiz: «Los oficiales carecían de número, de cohesión y de conciencia de clase; para ellos lo dominante era su relación personal con el patrono, lo que asemejaba su condición a la de un criado doméstico». ${ }^{(15)}$

-El sector terciario, es el más heterogéneo de los tres, pues abarca desde los comerciantes hasta los pequeños funcionarios locales, pasando por toda la gama de profesiones liberales, transportistas, marinos y sirvientes.

Los más cotizados son los comerciantes que reciben una media de dotes de 1871 libras, 15 sueldos y 6 dineros, lo que indica su importancia dentro de la escala social. Pero si a esto añadimos el hecho de que aportan las arras más altas con una media de 2.166 libras, 14 sueldos y 11 dineros, conocemos realmente su poder económico, que les permitirá ascender en la escala social.

Por su parte, las profesiones liberales gozan también de un interesante prestigio social que les aporta unas dotes medias de 573 libras, 13 sueldos y 10 dineros y pese a aportar escasas arras, algunos consiguen un mayor prestigio social, e incluso los hay que lucen entre su nombre el tratamiento de don, al igual que ocurre con algunos comerciantes.

Sin embargo, en el caso de transportistas y marinos, cambia el panorama; la media de las dotes que reciben ronda las 200 libras y su movilidad social es escasa.

Tras este esbozo de la estructura socioprofesional de Alicante, pasaremos a fijar los rasgos fundamentales de la misma y profundizaremos en ella detenién- 
donos en resaltar los matices más característicos de cada grupo socioprofesional, para lo cual, los hemos agrupado en 8 apartados: Nobleza local, comerciantes, profesiones liberales, maestros, marinos y transportistas, funcionarios locales, oficiales y artesanos no calificados y por último, campesinos.

El criterio que hemos seguido para esta clasificación ha sido el de las cantidades medias de dotes recibidas en los distintos oficios.

Con este fin, hemos elaborado el cuadro 4, en el que se aprecia que la nobleza local y los comerciantes acaparan la mayor cantidad de dinero de las dotes, mientras que los campesinos, aunque tienen el mayor número de dotes, disfrutan de una dote media casi inapreciable en comparación con la que le corresponde a la nobleza local o a los comerciantes que son los grupos que reciben las dotes más considerables, seguidos muy de lejos por los profesionales y los maestros.

\section{CUADRO 4}

Distribución del número de dotes por grupos socioprofesionales, 1750-1775

\begin{tabular}{|c|c|c|c|c|c|c|}
\hline GRUPOS S/P & $\begin{array}{c}N= \\
\text { um. } \\
\text { dotes }\end{array}$ & $\%$ & $\begin{array}{c}\text { Dinero } \\
\text { total }\end{array}$ & $\%$ & $\begin{array}{c}\text { Media } \\
\text { dotes }\end{array}$ & $\%$ \\
\hline Nobleza local.. & 22 & 9,3 & 26.337 .350 & 53,6 & 1.198 .970 & 59,5 \\
\hline Comerciantes & 32 & 13,5 & 14.375 .240 & 29,2 & 449.226 & 22,2 \\
\hline Profesiones liberales..... & 10 & 4,2 & 1.376 .867 & 2,8 & 137.687 & 6,8 \\
\hline Maestros $\ldots \ldots \ldots \ldots \ldots \ldots$ & 35 & 14,8 & 2.468 .603 & 5,0 & 70.531 & 3,5 \\
\hline Marinos y transportistas & 12 & 5,0 & 591.590 & 1,2 & 49.802 & 2,3 \\
\hline Funcionariado .............. & 8 & 3,3 & 374.883 & 0,7 & 46.860 & 2,3 \\
\hline $\begin{array}{l}\text { Oficiales y no califica- } \\
\text { dos }\end{array}$ & & & & & & \\
\hline Campesinos ........ & 82 & 34,7 & 2.256 .110 & 4,5 & 26.320 & 1,3 \\
\hline TOTAL ... & 236 & 100,0 & 49.101 .813 & 100,0 & 2.014 .981 & 100,0 \\
\hline
\end{tabular}

FUENTE: A.H.P.A. Protocolos. Elaboración propia

Por su parte el cuadro 5, referente a las arras, confirma la impresión que nos causaron las dotes, con la diferencia de que ahora la mayor cantidad de dinero no es la aportada por la nobleza, sino la que aportan los comerciantes, lo cual es lógico, pues éstos pretenden obtener un mayor prestigio social, y el modo de conseguirlo es contrayendo matrimonio con hijas de la nobleza local, para lo cual; han de proveer a sus hijos de sustanciosas arras.

Esta importancia de la nobleza local y los comerciantes que se desprende del análisis de los contratos matrimoniales, es reflejo de la situación socioeconómica en la que se encuentra Alicante en el siglo XVIII, con una nobleza que controla la producción agrícola más importante, la vitícola, y que además, «como conjunto fuertemente estructurado ejercían una influencia incontestable en el poder político dominando enteramente el gobierno municipal y la «Junta de inhibición de vinos forasteros», institución reguladora del comercio del vino alicantino», ${ }^{(16)}$ y un 
grupo de comerciantes que dada la inclinación económica de Alicante hacia su puerto, gozaban de unos beneficios más que respetables, máxime en momentos de progreso económico como ocurre en el siglo XVIII.

\section{CUADRO 5}

Distribución del número de arras por grupos socioprofesionales, 1750-1775

\begin{tabular}{|c|c|c|c|c|c|c|}
\hline GRUPOS $S / P$ & $\begin{array}{c}N{ }^{\prime} \\
\text { um. } \\
\text { arras }\end{array}$ & $\%$ & $\begin{array}{c}\text { Dinero } \\
\text { total }\end{array}$ & $\%$ & $\begin{array}{c}\text { Media } \\
\text { arras }\end{array}$ & $\%$ \\
\hline Nobleza local... & 12 & 23,0 & 5.943 .158 & 41,4 & 495.263 & 39,9 \\
\hline Comerciantes........... & 14 & 26,9 & 7.280 .263 & 50,7 & 520.091 & 41,9 \\
\hline Profesiones liberales..... & 3 & 5,7 & 83.760 & 0,5 & 27.920 & 2,2 \\
\hline Maestros .................... & 1 & 1,9 & 48.000 & 0,3 & 48.000 & 3,8 \\
\hline Marinos y transportistas & 4 & 7,6 & 173.728 & 1,2 & 52.802 & 4,2 \\
\hline Funcionariado ............ & 3 & 5,7 & 24.480 & 0,1 & 8.160 & 0,6 \\
\hline Oficiales y no califica- & & & & & & \\
\hline 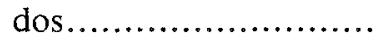 & 3 & 5,7 & 77.160 & 0,5 & 25.720 & 2,0 \\
\hline Campesinos ............... & 12 & 23,0 & 712.003 & 4,9 & 60.727 & 4,9 \\
\hline TOTAL . & 52 & 100,0 & 14.342 .552 & 100,0 & 1.238 .610 & 100,0 \\
\hline
\end{tabular}

FUENTE: A.H.P.A. Protocolos. Elaboración propia

Mientras que por el contrario, los campesinos evidencian también con sus escasas dotes y arras, su penosa situación económica.

Además, gracias a los contratos matrimoniales, también podemos estudiar las alianzas matrimoniales entre los distintos grupos socioprofesionales. Sin embargo, hay que aclarar que no es excesivamente frecuente que los contratos matrimoniales reflejen los datos referentes a la profesión del novio y del padre de la novia, como sería de desear; esto sólo ocurre en los 81 casos que se ven reflejados en el cuadro 6.

Sin embargo, para interpretar correctamente este cuadro, hay que indicar que tanto dentro del grupo de los comerciantes, como del de las profesiones liberales, se ven incluidos algunos nobles que son quienes dan ocasión a los 8 casos de comerciantes casados con miembros de la nobleza y los 3 casos que dentro del grupo de los profesionales, contraen matrimonio con nobles.

De todos modos, en líneas generales, podríamos afirmar que los grupos socioprofesionales que más alianzas matrimoniales establecen entre sí, son los comerciantes, los profesionales y los maestros; mientras que nobles y campesinos, se prestan más a matrimonios dentro de su propio grupo.

Para terminar, vamos a dedicar la última parte del presente artículo a efectuar un análisis más detenido de todos los grupos socioprofesionales que más arriba indicamos.

-El estamento nobiliario ve reflejada su gran importancia dentro de la so- 
ciedad alicantina en las altas cantidades que reciben sus miembros en concepto de dotes, lo que les proporciona la dote media más alta de cuantos grupos socioprofesionales hemos analizado: 4.995 libras, 14 sueldos y 2 dineros.

\section{CUADRO 6}

Enlaces matrimoniales entre los distintos grupos socioprofesionales

\begin{tabular}{|c|c|c|c|c|c|c|c|c|c|}
\hline$A$ & Nob. & Com. & P.L. & Mtr. & M.T. & Fun. & Ofi. & Cam. & Sir \\
\hline Nob. .......... & 25 & & & & & & & & \\
\hline Com............ & 8 & 7 & 2 & 2 & & & & & 2 \\
\hline P.L. $\ldots \ldots \ldots \ldots$ & 3 & & 2 & 1 & & & & & \\
\hline Mtr............ & & 1 & 1 & 1 & 1 & & & & 1 \\
\hline М.Т.......... & & & & & & & & & 1 \\
\hline Fun ................ & & & 1 & 2 & 1 & & & 1 & 3 \\
\hline $\begin{array}{l}\text { Ofi............... } \\
\text { Cam............ }\end{array}$ & & & 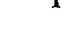 & 1 & & & & 12 & 1 \\
\hline Sir............ & & & & & & & & & 1 \\
\hline
\end{tabular}

$\mathrm{A}=\quad$ Grupo socioprofesional del padre de la novia

$\mathrm{B}=\quad$ Grupo socioprofesional del novio

Nob. nobleza local Fun. funcionariado local

Com. comerciantes Ofi. oficiales y no calificados

P.L. profesiones liberales Cam. campesinos

Mtr. Maestros Sir. Sirvientes

M.T. Marinos y transportistas

FUENTE: A.H.P.A. Protocolos. Elaboración propia

De este modo, como se aprecia en el cuadro 7, el mayor número de dotes se encuentra entre las 1.000 y las 1.999 libras, apreciándose un progresivo aumento de las dotes a medida que las cantidades que se entregan son más importantes.

En cuanto a las arras, conocen su número máximo entre las 1.000 y 1.999 libras, pero las hay también entre 0 y 99 libras, lo que nos indica que los hijos de la nobleza local no debían encontrar muchos obstáculos para contraer matrimonio con otras casas nobles.

Por lo que respecta a los bienes que componen esas altas dotes, como se aprecia en el cuadro 8, hay un predominio de los bienes muebles e inmuebles, mientras que las cantidades de dinero en muchos casos se refieren a pensiones anuales, siendo escasas las entregas de dinero efectivo, en contraste con lo que luego veremos en el caso de los comerciantes. 


\section{CUADRO 7}

Distribución de frecuencias agrupadas, absolutas y porcentuales del número de dotes y arras de nobles, según la cantidad de dinero que se otorga en allas

\begin{tabular}{ccccc}
\hline Libras & $N .^{\circ}$ dotes & $\%$ & $N .^{\circ}$ arras & $\%$ \\
\hline $0-99$ & 0 & 0 & 3 & 33,3 \\
$100-199$ & 1 & 4,5 & 0 & 0 \\
$200-299$ & 0 & 0 & 0 & 0 \\
$300-399$ & 1 & 4,5 & 0 & 0 \\
$400-499$ & 2 & 9 & 0 & 0 \\
$500-599$ & 1 & 4,5 & 0 & 0 \\
$600-699$ & 1 & 4,5 & 0 & 0 \\
$700-799$ & 1 & 4,5 & 0 & 0 \\
$800-899$ & 0 & 0 & 1 & 11,1 \\
$900-999$ & 1 & 4,5 & 0 & 0 \\
$1000-1999$ & 4 & 18,2 & 4 & 44,4 \\
$2000-2999$ & 2 & 9 & 0 & 0 \\
$3000-3999$ & 2 & 9 & 0 & 0 \\
$4000-4999$ & 1 & 4,5 & 0 & 0 \\
$5000-5999$ & 1 & 4,5 & 0 & 0 \\
$6000-6999$ & 2 & 9 & 0 & 0 \\
$7000-7999$ & 0 & 0 & 0 & 0 \\
$8000-8999$ & 0 & 0 & 0 & 0 \\
$9000-9999$ & 0 & 0 & 0 & 0 \\
10.000 y más & 2 & 9 & 1 & 11,1 \\
TOTAL & 22 & 100,0 & 9 & 100,0 \\
\hline
\end{tabular}

FUENTE: A.H.P.A. Protocolos. Elaboración propia

\section{CUADRO 8}

Núnero de dotes y de arras de los hidalgos según el tipo de bienes que se aportan en ellas

\begin{tabular}{|c|c|c|}
\hline Tipo de bienes & $N .^{\circ}$ de dotes & $N .^{\circ}$ de arras \\
\hline Dinero efectivo $\ldots \ldots \ldots \ldots \ldots \ldots \ldots$ & 3 & 1 \\
\hline Bienes muebles ......................... & 6 & 1 \\
\hline Bienes inmuebles ...................... & 1 & 0 \\
\hline Dinero y bienes muebles .............. & 9 & 1 \\
\hline Dinero y bienes inmuebles ........... & 0 & 2 \\
\hline Bienes muebles e inmuebles.......... & 1 & 0 \\
\hline Dinero, muebles e inmuebles ......... & 2 & 0 \\
\hline No hay datos ............................ & 3 & 7 \\
\hline TOTAL ..... & 25 & 12 \\
\hline
\end{tabular}

FUENTE: A.H.P.A. Protocolos. Elaboración propia 
Por otra parte, se trata del grupo más hermético en cuanto al establecimiento de alianzas matrimoniales con otros grupos socioprofesionales, hasta tal punto que no hemos logrado encontrar un solo hijo de familia noble que contrajera matrimonio con la hija de un plebeyo, mientras que hemos encontrado cuatro contratos matrimoniales en que el novio no era noble y la novia sí (aunque no de las familias más señeras de la ciudad), en los cuales las dotes eran muy bajas o las arras elevadas.

Ahora bien, el que la nobleza normalmente no contrajera matrimonio con plebeyos, no es óbice para que dentro del estamento nobiliario se crearan grandes intereses por contraer determinados matrimonios con las familias más señaladas de la ciudad, pues no hay que olvidar que el estamento nobiliario recoge en sus filas una gran gama de calidades, que van desde la nobleza titulada hasta los simples ciudadanos. (17) De ahí que incluso dentro del estamento noble las alianzas matrimoniales sean un medio usual de adquirir prestigio, emparentando con casas nobles más importantes, cruzando continuamente sus apellidos y creando una maraña de enlaces matrimoniales en la que resulta difícil entrar, ya no sólo a una familia plebeya, sino también a los ciudadanos que hubiesen adquirido su hidalguía recientemente.

Por último, las dotes inferiores a 1.000 libras, se explican por la existencia de determinadas casas que con el paso del tiempo se empobrecen, sobre todo aquellas ramas que fundan los hijos excluidos del mayorazgo, que en muchas ocasiones se ven obligados a ingresar en la milicia, en otras a desempeñas profesiones liberales (la más usual es la de abogado) y en otras ejerciendo cargos civiles al servicio del rey o en el peor de los casos del ayuntamiento, además de los que ingresaban en el clero.

Resumiendo: la nobleza local representa la cúspide de la pirámide social alicantina, y no sólo por los privilegios jurídicos que sin duda gozaban, sino también por su fuerza económica reflejada en las elevadas dotes que eran capaces de aportar.

-El grupo socioprofesional de los comerciantes, como se puede apreciar en el cuadro 9 , es bastante heterogéneo, pudiendo distinguirse fundamentalmente

\section{CUADRO 9}

Núnero de dotes, dinero total y media, de los comerciantes según la profesión que se especifica en las actas

\begin{tabular}{|c|c|c|c|}
\hline Profesiones & N. ${ }^{\circ}$ de dotes & Dinero total & Media dotes \\
\hline Negociante. & 11 & 9.616 .503 & 874.228 \\
\hline Mercader..... & 2 & 1.283 .700 & 641.850 \\
\hline Comerciante.. & 5 & 2.067 .982 & 413.596 \\
\hline Tratante ....... & 10 & 1.154 .411 & 115.441 \\
\hline Corredor de mar. & 1 & 128.074 & 128.074 \\
\hline Tendero .................... & 3 & 124.560 & 41.520 \\
\hline TOTAL & 32 & 14.375 .230 & 2.214 .709 \\
\hline
\end{tabular}

FUENTE: A.H.P.A. Protocolos. Elaboración propia 
tres grupos: de una parte los negociantes, mercaderes y comerciantes, que a juzgar por las dotes que recibían, debía tratarse de los más acaudalados, por lo general mayoristas o que combinaban el comercio al por mayor con el comercio al detall; de otra parte el corredor público de mar y cambios y los tratantes, que estarían por debajo de los anteriores; y por último los tenderos, que son pequeños detallistas con dotes muy bajas.

En el cuadro 10 podemos apreciar cómo el mayor número de dotes se encuentra entre las 1.000 y 2.999 libras en consonancia con la media aritmética de las dotes de comerciantes que es de 1.871 libras, 15 sueldos y 6 dineros.

\section{CUADRO 10}

Distribución de frecuencias agrupadas, absolutas y porcentuales del número de dotes y arras de comerciantes, según la cantidad de dinero que se aporta en allas

\begin{tabular}{ccccc}
\hline Libras & $N^{\circ}$ dotes & $\%$ & $N^{\circ}{ }^{o}$ arras & $\%$ \\
\hline $0-99$ & 2 & 6,2 & 1 & 7,1 \\
$100-199$ & 4 & 12,5 & 4 & 28,5 \\
$200-299$ & 1 & 3,1 & 0 & 0 \\
$300-399$ & 3 & 9,3 & 1 & 7,1 \\
$400-499$ & 3 & 9,3 & 1 & 7,1 \\
$500-599$ & 3 & 9,3 & 0 & 0 \\
$600-699$ & 1 & 3,1 & 0 & 0 \\
$700-799$ & 0 & 0 & 1 & 7,1 \\
$800-899$ & 0 & 0 & 0 & 0 \\
$900-999$ & 1 & 3,1 & 0 & 0 \\
$1000-1999$ & 6 & 18,7 & 1 & 7,1 \\
$2000-2999$ & 5 & 156 & 2 & 14,3 \\
$3000-3999$ & 0 & 0 & 1 & 7,1 \\
$4000-4999$ & 1 & 3,1 & 0 & 0 \\
$5000-5999$ & 1 & 3,1 & 0 & 0 \\
$6000-6999$ & 0 & 0 & 1 & 7,1 \\
$7000-7999$ & 0 & 0 & 0 & 0 \\
$8000-8999$ & 0 & 0 & 0 & 0 \\
$9000-9999$ & 0 & 0 & 0 & 0 \\
10.000 y más & 1 & 3,1 & 1 & 7,1 \\
TOTAL.. & 32 & 100,0 & 14 & 100,0 \\
\hline
\end{tabular}

FUENTE: A.H.P.A. Protocolos, Elaboración propia

De todos modos se aprecian dos prupos bien definidos: los que reciben entre 0 y 699 libras, y los que reciben entre 900 y 5.999 libras.

Al primer grupo (de 0 a 699 libras), pertenecerían los comerciantes calificados como tenderos, tratantes y corredores. Los tratantes serían comerciantes de puerta abierta, con un capital modesto y que en su mayoría no harían normalmente transacciones al por mayor. Por su parte, los tenderos no tenían peso algu- 
no dentro de la clase comerciante de la ciudad, limitándose a atender su pequeña tienda y disponiendo de un capital más bien pequeño.

El grupo verdaderamente importante era el de los negociantes, mercaderes y comerciantes, que recibían dotes superiores a las 900 libras y casi siempre de más de 1.000 libras. Ellos eran los que controlaban la vida comercial de la ciudad, lo cual es importante, sobre todo si pensamos que la vida económica alicantina dependía en gran medida de su puerto.

El prestigio social y económico de los comerciantes, debió ir en aumento a lo largo del siglo XVIII, pues según datos recogidos por Enrique Giménez de los años 1731,1732 y 1797 , se incrementó el número de comerciantes de puerta cerrada un $78,2 \%$, disminuyendo los minoristas un $10,6 \%$; incluso podemos encontrar 8 nobles dedicados al comercio, todos ellos con dotes superiores a las 1.000 libras. Pero además, podemos aportar ejemplos como el de Thomas Caturla, que en 1753 y 1756 aparece como un comerciante más, casando a sus tres hijas y dotándolas espléndidamente, ${ }^{(18)}$ y en 1809 aparecen dos de sus descendientes catalogados como nobles en una nómina encontrada en el Archivo Municipal de Alicante, de nobles y abogados que en ese año vivían en Alicante. ${ }^{(19)}$

Otro dato de gran interés respecto a los comerciantes, nos lo proporciona el análisis del tipo de bienes que se entregan tanto en las dotes como en las arras (cuadro 11), apreciándose la importancia de las cantidades de dinero en efectivo entregadas, acompañada generalmente por bienes muebles.

\section{CUADRO 11}

Núnero de dotes y de arras de los comerciantes según el tipo de bienes que se aportan en ellas

\begin{tabular}{|c|c|c|}
\hline Tipo de bienes & N. ${ }^{\circ}$ de dotes & N. ${ }^{\circ}$ de arras \\
\hline Dinero efectivo ......................... & 1 & 0 \\
\hline Bienes muebles $\ldots . . \ldots \ldots \ldots \ldots \ldots \ldots$. & 8 & 0 \\
\hline Dinero y bienes muebles ............... & 12 & 2 \\
\hline Dinero, muebles e inmuebles ........ & 3 & 1 \\
\hline Bienes muebles e inmuebles.......... & 1 & 1 \\
\hline No hay datos ........................ & 7 & 11 \\
\hline TOTAL $\ldots \ldots \ldots \ldots \ldots \ldots \ldots \ldots \ldots$ & 32 & 15 \\
\hline
\end{tabular}

FUENTE: A.H.P.A. Protocolos. Elaboración propia

El dinero en efectivo se entregaba en cantidades bastante respetables, lejos de las cantidades simbólicas que acostumbran a entregar labradores y artesanos. Pero además, también es frecuente la entrega de pagarés de varias personas, que servían de complemento a herencias y otras cantidades de dinero que constituían el grueso de la dote, mientras que los bienes inmuebles son muy escasos y nunca de fincas rústicas, lo que también nos indica el poco dinero que los comerciantes invertían en el campo. 
En cuanto a los grupos socioprofesionales con los que suelen contraer alianzas matrimoniales, hay que distinguir entre los grupos en que anteriormente los dividimos.

El grupo de tratantes y tenderos, no podían aspirar a casar con hijas de familias ricas. De este modo, los tenderos se solían conformar con contraer matrimonio con alguna sirvienta. Mientras que por su parte los tratantes disponían de una situación económica más saneada y casaban con hijas de otros tratantes o de maestros, que debían gozar de una estima social similar a la suya.

Por lo que se refiere a los comerciantes, mercaderes y negociantes, gozaban de mayor bienestar económico, lo que les abría un mayor abanico de posibilidades a la hora de elegir esposa. De ahí que aunque predominan los matrimonios con hijas de otros comerciantes de su misma categoaría, también enlazan con hijas de profesionales.

Para concluir, digamos que los comerciantes ocupan un lugar de privilegio en cuanto a las dotes que reciben, reflejo de la situación preponderante que ocupan dentro de la economía alicantina. Por otra parte, las posibilidades de ascenso en la escala social en el antiguo régimen son muy limitadas, pero no son imposibles y los comerciantes son un claro ejemplo de ello.

- Las profesiones liberales que hemos encontrado reflejadas en los contratos matrimoniales analizados son las siguientes: notarios; escribanos, abogados, cirujanos y escriturarios.

Los mejor situados, si atendemos a las dotes medias recibidas por los mienbros de estas profesiones son los notarios, seguidos de escribanos y abogados, con 240.000 dineros valencianos, 187.941 dineros valencianos y 141.548 dineros valencianos respectivamente, que los coloca a mucha distancia de escriturarios y cirujanos, cuyas dotes medias sólo alcanzan en el caso de los primeros $15.410 \mathrm{di}$ neros valencianos y 4.296 dineros valencianos para los segundos.

De este modo, se puede afirmar que los notarios, escribanos y abogados, debían tener unos ingresos económicos y una categoría social importantes, tanto es así que los dos abogados que hemos encontrado eran hidalgos, que naturalmente casaban con hijas de otros hidalgos, sin que ello les costara el pago de unas arras cuantiosas.

Estas profesiones con prestigio social, casaban sin problemas con hijas de familias con una categoría social importante, e incluso casaban a sus hijas con miembros de las capas altas del comercio de la ciudad.

Sin embargo, los cirujanos y los escriturarios debían disfrutar de unos ingresos escasos, recibiendo dotes que en ningún caso llagaban a las 300 libras $\mathbf{( 7 2 . 0 0 0}$ dineros valencianos), y contrayendo enlaces matrimoniales con maestros y funcionarios locales de pequeño rango.

Esta división entre los dos grupos de profesiones, se aprecia claramente en el cuadro 12. Unos con altas dotes, coincidiendo los máximos con los enlaces entre hidalgos; y otro inferior a las $\mathbf{3 0 0}$ libras, donde se encuentran junto a cirujanos y escriturarios algunos escribanos.

Por lo que respecta a las arras, vemos como todas ellas se encuentran por debajo de las 300 libras, lejos ya de las altas arras que se pagaban entre la nobleza local y los comerciantes, prueba evidente de que a partir de este grupo sociopro- 
fesional y en los otros grupos que nos quedan por analizar, los intereses económicos y de todo tipo que juegan en los distintos enlaces matrimoniales son cada vez menores.

\section{CUADRO 12}

Distribución de frecuencias agrupadas absolutas y porcentuales del número de dotes y de arras de profesionales, según la cantidad de dinero que se aporta en ellas

\begin{tabular}{rcrcc}
\hline Libras & $N{ }^{\circ}$ dotes & $\%$ & $N .^{\circ}$ arras & $\%$ \\
\hline $0-99$ & 2 & 20 & 1 & 33,3 \\
$100-199$ & 1 & 10 & 1 & 33,3 \\
$200-299$ & 3 & 30 & 1 & 33,3 \\
$300-399$ & 0 & 0 & 0 & 0 \\
$400-499$ & 1 & 10 & 0 & 0 \\
$500-599$ & 0 & 0 & 0 & 0 \\
$600-699$ & 0 & 0 & 0 & 0 \\
$700-799$ & 0 & 0 & 0 & 0 \\
$800-899$ & 0 & 0 & 0 & 0 \\
$900-999$ & 0 & 0 & 0 & 0 \\
$1000-1199$ & 2 & 20 & 0 & 0 \\
$2000-2999$ & 1 & 10 & 0 & 0 \\
3000 y más & 0 & 0 & 0 & 0 \\
TOTAL & 10 & 100 & 3 & 100,0 \\
\hline
\end{tabular}

FUENTE: A.H.P.A. Protocolos. Elaboración propia

Otro dato interesante sobre este grupo socioprofesional nos lo proporciona la relación de objetos que acompaña sus dotes, apreciándose un predonio absoluto de los bienes muebles y escasísimas cantidades de dinero en efectivo, hecho éste que se repite también con escasas variaciones en el resto de los grupos que quedan por analizar.

Para resumir, diremos que las profesiones liberales gozaban de un prestigio social aceptable, si bien su poder económico podríamos calificarlo de modesto, dependiendo de la profesión específica que desempeñasen. Sin embargo y pese a sus modestos ingresos económicos, pueden contraer matrimonio con hijas de familias que se encuentran en grupos socioprofesionales más poderosos que el suyo, gracias al prestigio social de sus profesiones.

- Hemos dividido a los artesanos en dos grupos para su mejor estudio: el primero está formado por los maestros y el segundo por los oficiales, incluyendo en este último a todos aquéllos de los que no se ha especificado si son maestros $u$ oficiales, ya que por la dote media que reciben se pueden equiparar a los segundos.

Las diferencias existentes entre uno y otro grupo, se aprecian claramente en el cuadro 13. En él vemos cómo hay un gran número de maestros, concretamente el $62,8 \%$, que reciben dotes entre las 0 y las 299 libras, y que por lo tanto se encuentran al mismo nivel que los oficiales que están todos entre estas dos cifras. 
CUADRO 13

Distribución de frecuencias agrupadas, absolutas y porcentuales del número de maestros, oficiales y artesanos sin calificar, según el dinero que se aporta en ellas

\begin{tabular}{|c|c|c|c|c|c|c|}
\hline \multirow[b]{2}{*}{ Libras } & \multirow{2}{*}{$\begin{array}{l}\text { Maestros } \\
N .{ }^{\circ} \text { dotes }\end{array}$} & \multicolumn{3}{|c|}{ Oficiales } & \multicolumn{2}{|c|}{ Artesanos sin calif. } \\
\hline & & $\%$ & N. ${ }^{\circ}$ dotes & $\%$ & N. ${ }^{\circ}$ dotes & $\%$ \\
\hline $0-99$ & 4 & 11,4 & 6 & 40,0 & 6 & 30 \\
\hline $100-199$ & 11 & 31,4 & 8 & 53,3 & 8 & 40 \\
\hline $200-299$ & 7 & 20,0 & 1 & 6,6 & 2 & 10 \\
\hline 300-399 & 4 & 11,4 & 0 & 0 & 2 & 10 \\
\hline $400-499$ & 4 & 11,4 & 0 & 0 & 1 & 5 \\
\hline $500-599$ & 1 & 2,8 & 0 & 0 & 1 & 5 \\
\hline $600-699$ & 1 & 2,8 & 0 & 0 & 0 & 0 \\
\hline 700-799 & 1 & 2,8 & 0 & 0 & 0 & 0 \\
\hline 800-899 & 1 & 2,8 & 0 & 0 & 0 & 0 \\
\hline 900-999 & 0 & 0,0 & 0 & 0 & 0 & 0 \\
\hline 1000 y más & 1 & 2,8 & 0 & 0 & 0 & 0 \\
\hline TOTAL & 35 & 100,0 & 15 & 100,0 & 20 & 100,0 \\
\hline
\end{tabular}

FUENTE: A.H.P.A. Protocolos. Elaboración propia

Por lo tanto, hay un gran número de maestros cuya situación económica, a tenor de las dotes que reciben, no se diferencia apenas de la que tienen los oficiales, lo que nos indica una tendencia a la proletarización de gran cantidad de maestros que no consiguen con el trabajo en su taller reunir lo necesario para sobrevivir, por lo que engrosarían el número de los asalariados.

Ahora bien, junto a estos maestros emprobrecidos, hay unos cuantos que sí tienen trabajo y aumentan con él su capital, consiguiendo de este modo una prosperidad tal que incluso algunos de ellos amplían su campo de actividad con el comercio al por mayor. Estos maestros son los que reciben dotes superiores a las 500 libras y que pueden llegar hasta las 1.000 libras en algún caso.

De este modo, los maestros según su situación económica, contraen matrimonio con hijas de otros maestros, de marinos y transportistas y en el caso de los mejor situados, con hijas de profesionales e incluso de tratantes.

Por su parte, los oficiales se conforman con casar con la hija del maestro para el que trabajan o con la de algún marino.

Hay que señalar que ningún artesano casa con un campesino ni viceversa.

Esa diferencia clara entre las dotes de unos maestros y otros y el menor número de oficiales que de maestros, según nuestros datos, así como también la similitud en la cuantía de las dotes que reciben los oficiales y los maestros pobres, pueden ser considerados como indicadores de la decadencia del sistema gremial en el siglo XVIII.

-Los pequeños funcionarios locales desempeñaban misiones burocráticas 
rutinarias, como son las de alguacil, guardia de aduanas, guardias del falucón y cobrador de rentas, y en ningún caso tomaban parte en el gobierno de la ciudad.

Como se ve, son cargos de los que no se pueden extraer grandes beneficios, ya que los puestos de mayor poder eran ocupados por la nobleza local que dominaba por completo el ayuntamiento de la ciudad.

Sin embargo, los beneficios que extraían de estos puestos, eran suficientes para elevarlos por encima de la gran masa de trabajadores del campo y labradores, al menos así parecen indicarlo las dotes que recibían, que alcanzan la media de 46.860 dineros valencianos, lo que les sitúa a la altura de los oficiales. Además todas ellas aparecen concentradas entre las 0 y las 499 libras de dote, lo que nos indica que las diferencias entre ellos son mínimas.

Para resumir, digamos que es el grupo socioprofesional del que menor número de actas matrimoniales hemos encontrado, lo que nos hace pensar en un grupo bastante reducido y a juzgar por sus dotes y sus escasísimas arras, no muy bien pagado, aunque sí lo suficiente para cubrir sus necesidades y no sufrir los agobios económicos de los campesinos.

- Sólo nos queda ya por analizar el campesinado, del que hemos hecho múltiples referencias a lo largo del artículo, especialmente al analizar el sector primario, por lo que únicamente cabría recordar que es el grupo más numeroso y el que recibe las dotes más bajas, prueba todo ello de su lamentable situación.

\section{NOTAS}

(1) Jacques Lafon: Regimes matrimoniaux et mutations sociales. Les époux bourdelais 14501550, París, 1972, p. 16.

(2) Tirat: «Problemas de methode en histoire sociale» en Revue Historique Moderne et Contemporaine, 1963, pp. 201-218.

(3) Poussou «Experience aquitaine et methodologie des contrats de mariage au XVII ${ }^{\circ}$ siecle» en Annales du Midi, $\mathrm{n}^{\circ} 66,1964, \mathrm{pp} .61-67$.

(4) Carlo M. Cipolla: Historia económica de la Europa pre-industrial, Madrid, 1976, p. 42.

(5) John Lynch: España bajo los Autrias, Barcelona, 1975.

(6) Antonio Domínguez Ortiz: «Don Leandro Fernández de Moratín y la sociedad española de su tiempo» en Revista de la Universidad de Madrid, volumen X, $\mathrm{n}^{\circ} 35$. También forma parte este artículo de Hechos y figuras del siglo XVIII español, Madrid, 1980, $2^{\text {a }}$ edci. p. 302.

(7) Estas pragmáticas quedaron reflejadas en la ley 1, título 2 , libro 5 y la ley 5 , título 2 , libro 5 , de la Nueva Recopilación.

(8) A.H.P.A. Protocolos, P-H814, ff. 34-35v.

(9) A.H.P.A. Protocolos, P-109, ff. 406-412.

(10) Agnes Fine-Souriac: «Alliance et filiation en haute Provence au XVIII ${ }^{\circ}$ siècle» en $A n n a-$ les, mai-juin, 1977, p. 446.

(11) A. Domínguez Ortiz: Sociedad y Estado en el siglo XVIII español, Barcelona, 1981, $2^{\text {a }}$ edición, p. 327.

(12) Gonzalo Anes: El Antiguo Régimen: los Borbones, Madrid, 1978, $3^{\text {a }}$ edición, p. 164.

(13) E. Giménez: Alicante en el siglo XVIII. Economía de una ciudad portuaria en el antiguo régimen, Valencia, 1981, p. 191. 
(14) Las cantidades de dinero están expresadas en dineros valencianos.

(15) A. Domínguez Ortiz: Sociedad y estado en el siglo XVIII español, Barcelona, 1981, $2^{2}$ edición, p. 391.

(16) E. Giménez: Op. Cit., Valencia, 1981, p. 195.

(17) ver: Mario Madramany y Calatayud: Tratado de la nobleza de la Corona de Aragón especialmente del Reino de Valencia comparada con la de Castilla. Para ilustración de la Real Cédula del Señor don Luis I de 14 de agosto de 1724, en Valencia por Josef y Tomás de Orga, año MDCCLXXXVIII, pp. 13-20.

(18) A.H.P.A. Protocolos, P-103, ff. 35-35v; P-103, ff. 87-87v y P-106, ff. 53-53v.

(19) Martinez Morellá, Vicente: «Nómina de nobles y abogados residentes en Alicante en 1809», en Hidalguia, Madrid, VII, $n^{\circ} 35,1959, p p$. 509-512. 